\title{
Neurotrophins, cytokines, oxidative parameters and functionality in Progressive Muscular Dystrophies
}

\author{
CLARISSA M. COMIM ${ }^{1}$, GISIANE B. MATHIA ${ }^{2}$, ANDREZA HOEPERS ${ }^{1}$, LISIANE TUON $^{2}$, \\ FLÁVIO KAPCZINSKI ${ }^{4}$, FELIPE DAL-PIZZOL ${ }^{3}$, JOÃO QUEVEDO ${ }^{5,6}$ and MARIA I. ROSA ${ }^{2}$ \\ ${ }^{1}$ Programa de Pós-Graduação em Ciências da Saúde, Universidade do Sul de Santa Catarina, \\ Laboratório de Neuropatologia Experimental, Avenida Pedra Branca, 25, Pedra Branca, 88137-270 Palhoça, SC, Brasil \\ ${ }^{2}$ Programa de Pós-Graduação em Ciências da Saúde, Universidade do Extremo Sul Catarinense, \\ Laboratório de Epidemiologia, Avenida Universitária, 1105, Pinheirinho, 88806-000 Criciúma, SC, Brasil \\ ${ }^{3}$ Programa de Pós-Graduação em Ciências da Saúde, Universidade do Extremo Sul Catarinense, \\ Laboratório de Fisiopatologia Experimental, Avenida Universitária, 1105, Pinheirinho, 88806-000 Criciúma, SC, Brasil \\ ${ }^{4}$ Hospital de Clínicas de Porto Alegre, Centro de Pesquisas, Laboratório de Psiquiatria Molecular, \\ Rua Ramiro Barcelos, 2350, Santa Cecília, 90035-003 Porto Alegre, RS, Brasil \\ ${ }^{5}$ Programa de Pós-Graduação em Ciências da Saúde, Universidade do Extremo Sul Catarinense, \\ Laboratório de Neurociências, Avenida Universitária, 1105, Pinheirinho, 88806-000 Criciúma, SC, Brasil \\ ${ }^{6}$ The University of Texas Medical School at Houston, Center for Experimental Models in Psychiatry, \\ Department of Psychiatry and Behavioral Sciences, 6431, Fannin Street, 77030 Houston, TX, USA
}

Manuscript received on October 7, 2014; accepted for publication on December 19, 2014

\begin{abstract}
We investigated the levels of brain derived-neurotrophic factor (BDNF), cytokines and oxidative parameters in serum and tried to correlate them with the age and functionality of patients with Progressive Muscle Dystrophies (PMD). The patients were separated into six groups (case and controls pared by age and gender), as follows: Duchenne Muscular Dystrophy (DMD); Steinert Myotonic Dystrophy (SMD); and Limb-girdle Muscular Dystrophy type-2A (LGMD2A). DMD patients ( \pm 17.9 years old) had a decrease of functionality, an increase in the IL-1 $\beta$ and TNF- $\alpha$ levels and a decrease of IL-10 levels and superoxide dismutase activity in serum. SMD patients ( \pm 25.8 years old) had a decrease of BDNF and IL-10 levels and superoxide dismutase activity and an increase of IL- $1 \beta$ levels in serum. LGMD2A patients ( \pm 27.7 years old) had an decrease only in serum levels of IL-10. This research showed the first evidence of BDNF involvement in the SMD patients and a possible unbalance between pro-inflammatory and anti-inflammatory cytokine levels, along with decreased superoxide dismutase activity in serum of DMD and SMD patients.
\end{abstract}

Key words: Progressive Muscular Dystrophies, BNDF, cytokines, oxidative stress.

\section{INTRODUCTION}

Progressive Muscular Dystrophies (PMD) are a heterogeneous group of disorders that primarily affect skeletal muscles. It is characterized by

Correspondence to: Clarissa M. Comim

E-mail: clarissamc@gmail.com.br degeneration and regeneration of muscle fibers with muscle weakness as the primary symptom. Clinical and pathologic criteria have been used in the past for classification, but nowadays muscular dystrophies are mostly classified on a genetic basis (Emery 1998). 
Duchenne Muscular Dystrophy (DMD) is the most severe form of PMD worldwide. It is a fatal recessive $\mathrm{X}$-linked muscular disease affecting about 1 in 3500 live-born human males. This weakness is due to an irreversible ongoing degeneration of skeletal muscle and results in a loss of mobility at the beginning of the second decade and a fatal outcome in the third decade. The disease is the consequence of a mutation in the dystrophin gene (Koenig et al. 1989). Other PMD such as limb-girdle muscular dystrophy type 2A (LGMD2A) and Steinert Myotonic Dystrophy (SMD) also have properties and affect muscle fibers. SMD is the most common form of adult muscular dystrophy and it is a highly pleiotropic autosomal-dominant disease involving skeletal muscles, heart, lungs, gastrointestinal tract, bone, skin, and central and peripheral nervous system. The disorder is caused by amplification of an unstable trinucleotide (CTG) repeat in the 3' - untranslated region of a transcript encoding a serine/threonine kinase, on chromosome 19 (Harper 1989). LGMD is a genetically heterogeneous group of disorders that can be divided into two groups in relation to the pattern of inheritance: autosomal-dominant (LGMD1, A-E) and autosomal-recessive (LGMD2, A-I). The LGMD2A are caused by primary mutations in CAPN3 gene (Guglieri et al. 2005).

It is suggested that an increase of reactive oxygen species (ROS) production, chronic inflammation and fibrosis in skeletal muscle of PMD patients are associated with muscle function loss (Fanzani et al. 2013). While the link between inflammation with muscle damage and weakness is unclear, elevated oxidative stress has been proposed as a strong contributing mechanism (Tidball and WehlingHenricks 2007). Dystrophic muscle cells are more susceptible to reactive oxygen intermediates, which are traditionally considered to exert their effects via a direct toxic action on target cells (Chelly and Desguerre 2013). Furthermore, free radicals are known to be responsible for chemical and molecular damage of DNA, nucleotides, proteins, lipids, carbohydrates, and cell membrane structure (Ito et al. 2006). However, low reactive oxygen intermediate levels activate the Nuclear factor (NF)$\mathrm{kB}$, responsible for the regulation of the expression of genes involved in the inflammatory response as the interleukin (IL)-1 $\beta$, and tumor necrosis factor- $\alpha$ (TNF- $\alpha$ ). All of which were found to be elevated in dystrophin-deficient muscle and other types of PMD (Jamaluddin et al. 2007).

Some studies show that PMD patients present cognitive impairment(D'Angelo and Bresolin 2006). However, the involved mechanisms are still not clear. In animal models, cognitive impairment was also observed in DMD individuals (D'Angelo and Bresolin 2006). During the process of learning and memory formation, there is an important peptide involved: the brain-derived neurotrophic factor (BDNF) - a member of the neurotrophin family and the most widespread growth factor in the brain. BDNF is highly expressed in the hippocampus and has diverse functions in the adult brain as a regulator of neuronal survival, fast synaptic transmission and activity dependent synaptic plasticity (Bramham and Messaoudi 2005). Evidence suggests that deficits in BDNF signaling contribute to the pathogenesis of several major diseases and disorders that are associated to cognitive impairment such as Huntington's disease, Alzheimer's disease, and depression (Lu et al. 2014).

Finally, PMD are characterized by the primary wasting of skeletal muscle and more recently by the central nervous system (CNS) involvement. It is known that both oxidative stress and inflammation have important roles in the degenerative process in several diseases and that BDNF in serum is considered a good marker for lesions in the CNS since they can easily cross the blood brain barrier (BBB). Thus, the aim of this study was to investigate in the serum of PMD patients the levels of BDNF to evaluate the involvement to CNS and measure the levels of IL-1 $\beta,-10$ and TNF- $\alpha$ as well as oxidative 
parameters to evaluate the state of the skeletal muscle. The data are comparing disease stage by functionality and by age of the patients in order to understand the association of these parameters in the degeneration stages in PMD patients.

\section{MATERIALS AND METHODS}

\section{STUDY DESIGN}

We conducted a case-control study with patients enrolled in the Muscular Dystrophy Association of Southern Santa Catarina (ASCADIM), Brazil. The diagnosis of muscular dystrophy was established by clinical and neurological examination, family history, muscle biopsy with immunohistochemical analysis, and genetic tests when necessary. The Ethics Committee from UNESC approved this study.

\section{PATIENTS AND CONTROLS}

The cases were all patients of ASCADIM with a total of 29 patients with different PMD (no patient was on mechanical ventilation). From a total of 29 cases, there were five exclusions: 4 cases of LGMD2A and one case of SMD who had suffered a stroke, resulting in a total of 24 cases for the research, as follows: DMD ( $\mathrm{n}=7$, all males, mean age $=17.9( \pm 6.4)$ years old, 2 patients very dependent (used a wheelchair), 3 partially dependent and 2 independent); $\operatorname{SMD}(n=10$, 4 males and 6 females, mean age $=25.8( \pm 11.6)$ years old, 1 patient partially dependent and 9 independent); and LGMD2 $(\mathrm{n}=7,2$ males and 5 females, mean age $=27.7 \quad( \pm 13.1)$ years old, 1 patient partially dependent and 6 independent). This study followed the tenets of the Declaration of Helsinki. Informed consents were obtained from the subjects after the nature of the study was thoroughly explained. The control group consisted of healthy people without any disease, matched for gender and age.

\section{BLOOD COLLECTION}

A total volume of $10 \mathrm{~mL}$ of peripheral blood was collected from all cases and controls; the serum was separated and stored at $-80^{\circ} \mathrm{C}$ degrees.

\section{TEST OF FUNCTIONALITY}

The Barthel Index serves as a measure of functional independence in personal care and mobility of the patient. The instrument was developed to evaluate treatment outcomes of the chronic patients, it has been used with rehabilitation patients to predict length of stay, to estimate prognosis and to anticipate discharge outcomes. The test includes a 10 -item response with a four-point scale. It covers activities of daily living (ADL) such as personal toileting, feeding, mobility from bed to chair, transfers, bathing, walking, dressing, incontinence and going upstairs. A total of 10 activities are scored, and the values are then added to give a total score ranging from 0 (totally dependent) to 100 (completely independent). Thus, lower scores indicate greater dependency. This test can be interpreted as follows: score of 80-100: independent; score of 60-79: needs minimal help with ADL; score of 40-59: partially dependent; score of 20-39: very dependent; and score of $<20$ : totally dependent(Sinoff and Ori 1997).

\section{BDNF LEVELS}

BDNF levels were measured by anti-BDNF sandwich-ELISA, according to the manufacturer instructions (Chemicon, USA). Briefly, the serum was homogenized with $1 \mathrm{mM}$ phenylmethylsulfonyl fluoride and $1 \mathrm{mM}$ EGTA. Microtiter plates (96-well flat-bottom) were coated for $24 \mathrm{~h}$ with the samples diluted 1:2 in sample diluent. The plates were then washed four times with sample diluent, and a monoclonal anti-BNDF rabbit antibody diluted to $1: 1000$ in sample diluents was added to each well and incubated for $3 \mathrm{~h}$ at room temperature. After washing, a peroxidase conjugated anti-rabbit antibody (diluted 1:1000) was added to each well and incubated at room temperature for $1 \mathrm{~h}$. After addition of streptavidinenzyme, substrate and stop solution, the amount of BDNF was determined by absorbance in $450 \mathrm{~nm}$. A standard curve was produced and it ranged 
from 7.8 to $500 \mathrm{pg} / \mathrm{mL}$ of BNDF. This curve was obtained from a direct relationship between Optical Density and BDNF concentration. Total protein was measured using bovine serum albumin as a standard (Lowry et al. 1951).

\section{CyTOKINES LEVELS}

The concentration of cytokines (IL-1 $\beta,-10$, and TNF- $\alpha$ ) was determined by ELISA (R\&D Systems, Minneapolis, MN). All samples were assayed in duplicate. Briefly, the capture antibody $(13 \mathrm{~mL}$, contains $0.1 \%$ sodium azide) was diluted in phosphate-buffered saline (PBS), added to each well and left overnight at $4^{\circ} \mathrm{C}$. The plate was washed four times with PBS and 0.05\% Tween 20 (Sigma, St. Louis, MO, USA). The plate was blocked with $1 \%$ bovine serum albumin and incubated for $1 \mathrm{~h}$ at room temperature before washing four times with PBS and $0.05 \%$ Tween 20 . The samples and standards were added and the plate was incubated overnight at $4^{\circ} \mathrm{C}$. After washing the plate, detection antibody (concentration provided by the manufacturer) diluted in PBS was added. The plate was incubated for $2 \mathrm{~h}$ at room temperature. After washing the plate, streptavidin (DuoSet R\&D Systems, Minneapolis, MN, USA) was added and the plate was incubated for $30 \mathrm{~min}$. At last, color reagent o-phenylenediamine (Sigma, St. Louis, MO, USA) was added to each well and the reaction was allowed to develop in the dark for $15 \mathrm{~min}$. The reaction was stopped with the addition of $1 \mathrm{M}$ sulfuric acid to each well. The absorbance was read on a plate reader at $492 \mathrm{~nm}$ wave length (Emax, Molecular Devices, Minneapolis, MN, USA). Total protein was measured using bovine serum albumin as a standard (Lowry et al. 1951).

OXIDATIVE PARAMETERS

The formation of TBARS was measured during an acid-heating reaction (Esterbauer and Cheeseman 1990). The samples were mixed with $1 \mathrm{~mL}$ of trichloroacetic acid (TCA) $10 \%$ and $1 \mathrm{~mL}$ of thiobarbituric acid $0.67 \%$ and were then heated in a boiling water bath for $15 \mathrm{~min}$. TBARS was determined by the absorbance at $535 \mathrm{~nm}$. Oxidative damage to proteins was measured by the quantification of carbonyl groups based on the reaction with dinitrophenylhydrazine (DNPH) (Levine et al. 1994). Proteins were precipitated by the addition of $20 \%$ trichloroacetic acid and were redissolved in DNPH; the absorbance was read at $370 \mathrm{~nm}$. To determine CAT activity, the serum was sonicated in $50 \mathrm{mmoL} / \mathrm{L}$ phosphate buffer $(\mathrm{pH} 7.0)$, and the resulting suspension was centrifuged at 3000x $\mathrm{g}$ for $10 \mathrm{~min}$. The supernatant was used for enzyme assay. CAT activity was measured by the rate of decrease in hydrogen peroxide absorbance at $240 \mathrm{~nm}$ (Aebi 1984). SOD activity was assayed by measuring the inhibition of adrenaline autoxidation, as previously described (Bannister and Calabrese 1987). All biochemical measures were normalized to the protein content, with bovine albumin as standard (Lowry et al. 1951).

\section{Statistical AnAlYses}

Shapiro-Wilk normality test was used to determine parametric and non-parametric testing. Data were expressed as mean \pm standard error and were statistically analyzed with the Student's $t$-test for independent data. $P$ values less than 0.05 were considered statistically significant.

\section{RESULTS}

The present study sample included 48 subjects ( 24 cases and 24 controls). Eligible cases (outcome) included seven DMD, seven LGMD2 and ten SMD, with a total of 24 cases and 24 controls. There were no statistical differences regarding age in all groups. Regarding functionality there was a decrease in the DMD patients when compared with control group $(\mathrm{p}=0.002)$. In the DMD group, there were two patients very dependent, three partially dependent and two independent (Table I). 
TABLE I

Gender, functionality and age of DMD, SMD and LGMD2A patients. There weren't statistical differences regarding age in all groups. Regarding functionality, there was statistical difference only in the DMD patients. * $\mathbf{p}<0.05$, chi-square test.

\begin{tabular}{|c|c|c|c|c|c|c|c|c|c|}
\hline \multirow[b]{2}{*}{ Variables } & \multicolumn{3}{|c|}{$\begin{array}{c}\text { Duchenne Muscular } \\
\text { Dystrophy }\end{array}$} & \multicolumn{3}{|c|}{$\begin{array}{c}\text { Steinert Myotonic } \\
\text { Dystrophy }\end{array}$} & \multicolumn{3}{|c|}{$\begin{array}{c}\text { Limb-girdle Muscular } \\
\text { Dystrophy 2A }\end{array}$} \\
\hline & $\begin{array}{l}\text { Cases } \\
(\mathrm{n}=7)\end{array}$ & $\begin{array}{l}\text { Controls } \\
(\mathrm{n}=7)\end{array}$ & p-value & $\begin{array}{l}\text { Cases } \\
(\mathrm{n}=10)\end{array}$ & $\begin{array}{c}\text { Controls } \\
(\mathrm{n}=10)\end{array}$ & p-value & $\begin{array}{l}\text { Cases } \\
(\mathrm{n}=7)\end{array}$ & $\begin{array}{l}\text { Controls } \\
(\mathrm{n}=7)\end{array}$ & p-value \\
\hline \multicolumn{10}{|l|}{ Gender } \\
\hline male & 7 & 7 & & 4 & 4 & & 2 & 2 & \\
\hline female & 0 & 0 & & 6 & 6 & & 5 & 5 & \\
\hline Funcionality* & & & $0.002 *$ & & & 0.3 & & & 0.29 \\
\hline very dependent & 2 & 0 & & 0 & 0 & & 0 & 0 & \\
\hline partially dependent & 3 & 0 & & 1 & 0 & & 1 & 0 & \\
\hline independent & 2 & 7 & & 9 & 10 & & 6 & 7 & \\
\hline $\begin{array}{l}\text { Age (years) } \\
\text { mean (SEM) }\end{array}$ & $\begin{array}{l}17.9 \\
(6.4)\end{array}$ & $\begin{array}{l}17.9 \\
(6.5)\end{array}$ & 1.00 & $\begin{array}{c}25.8 \\
(11.6)\end{array}$ & $\begin{array}{c}25.8 \\
(11.6)\end{array}$ & 1.00 & $\begin{array}{c}27.7 \\
(13.1)\end{array}$ & $\begin{array}{c}27.7 \\
(13.2)\end{array}$ & 1.00 \\
\hline
\end{tabular}

Figure 1 shows the BDNF levels in serum of DMD, SMD and LGMD2A patients. There was a decrease in the BDNF levels in the SMD group when compared with controls $(\mathrm{t}=3.554 ; \mathrm{df}=18$; $\mathrm{p}=0.002)$. No statistical difference was observed when comparing DMD patients $(\mathrm{t}=-1.333 ; \mathrm{df}=15$; $\mathrm{p}=0.202)$ and LGMD2 $(\mathrm{t}=-0.094 ; \mathrm{df}=12 ; \mathrm{p}=0.927)$ with controls.

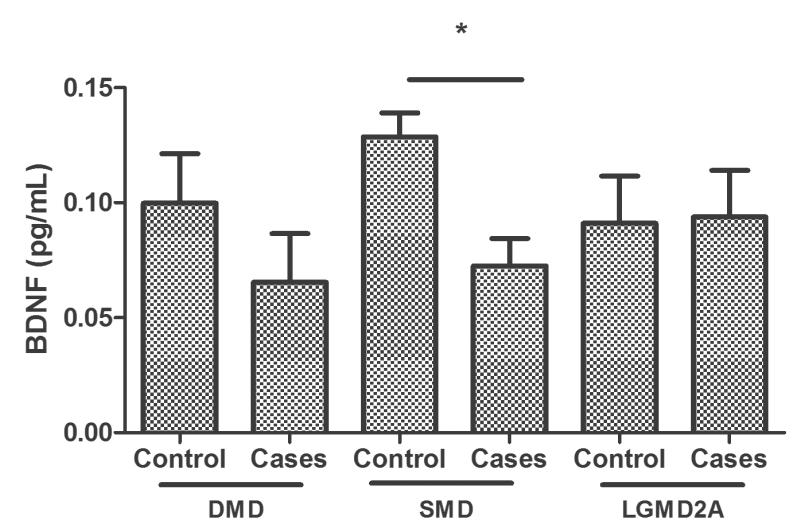

Figure 1 - BDNF levels in serum of Progressive Muscular Dystrophy patients. There was a decrease of BDNF levels in SMD patients when compared with control groups. Bars are expressed in mean and error of mean. ${ }^{*} \mathrm{p}<0.05$, Student t-test.
Figure 2 indicates the results of the oxidative parameters in serum of DMD, SMD and LGMD2A patients. There were no alterations in the lipid peroxidation (Figure 2A) as indicated by MDA equivalent levels $(\mathrm{p}>0.05)$, protein peroxidation (Figure 2B) as indicated by carbonyl levels ( $>0.05$ ) and catalase levels $(\mathrm{p}>0.05)$ (Figure $2 \mathrm{C})$. However, a decrease in the superoxide dismutase parameters in the DMD patients was observed $(\mathrm{t}=-3.641 ; \mathrm{df}=12$; $\mathrm{p}=0.010)$ and in the SMD group $(\mathrm{t}=-3.586 ; \mathrm{df}=18$; $\mathrm{p}=0.006$ ). There were not statistical difference in the LGDM2A group ( $>0.05$ ) when compared with control groups.

Figure 3 demonstrates the cytokines levels in serum of DMD, SMD and LGMD2A patients. There was an increase in IL-1 $\beta$ levels in the DMD $(\mathrm{t}=2.797 ; \mathrm{df}=12 ; \mathrm{p}=0.024)$ and $\mathrm{SMD}(\mathrm{t}=5.080 ; \mathrm{df}=18$; $\mathrm{p}=0.0001)$; a decrease in the IL-10 levels in the DMD $(\mathrm{t}=-.717 ; \mathrm{df}=12 ; \mathrm{p}=0.019), \operatorname{SMD}(\mathrm{t}=-3.371 ; \mathrm{df}=18$; $\mathrm{p}=0.003)$, and LGMD2A ( $\mathrm{t}=-2.552 ; \mathrm{df}=12 ; \mathrm{p}=0.042)$ patients when compared with controls. In addition, an increase in TNF- $\alpha$ levels only in the DMD patients $(\mathrm{t}=2.551 ; \mathrm{df}=12 ; \mathrm{p}=0.035)$ was observed. 

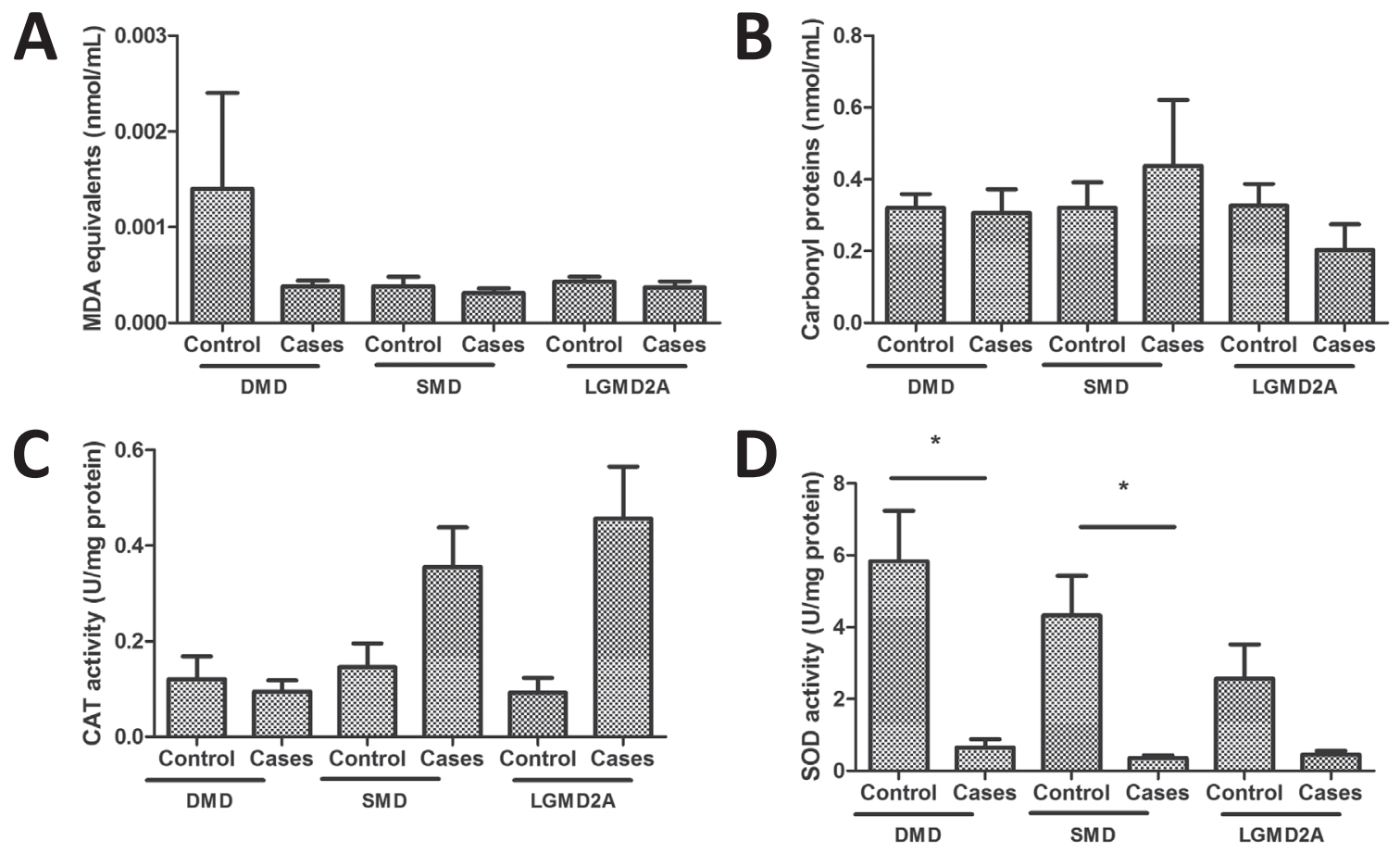

Figure 2 - Oxidative parameters in serum of Muscular Dystrophy patients. There were no alterations of MDA equivalents (A), Carbonyl (B), and CAT (C) in all groups analyzed. However, there was a decrease of SOD activity (D), activity in DMD and SMD patients. Bars are expressed in mean and error of mean. ${ }^{*} \mathrm{p}<0.05$, Student t-test.
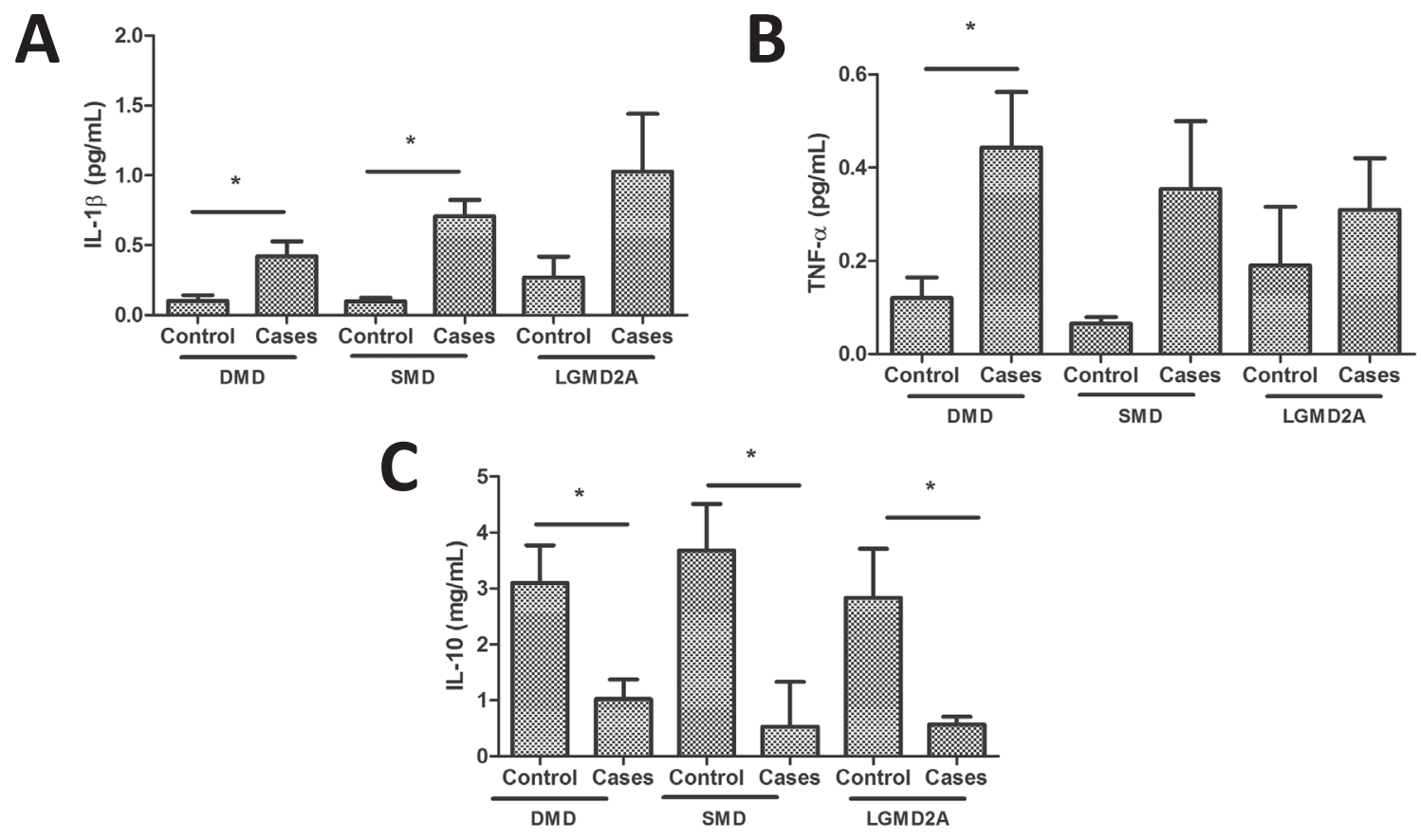

Figure 3 - Cytokines levels in serum of Muscular Dystrophy patients. There was an increase of IL-1 $\beta$ in DMD and SMD patients (A). TNF- $\alpha$ increased only in the DMD patients (B), and IL-10 decreased in all groups analyzed (C). Bars are expressed in mean and error of mean. $* \mathrm{p}<0.05$, Student t-test. 


\section{DISCUSSION}

In this study, DMD patients presented a decline in the functionality of those with the mean age of 17.9 years old. However, SMD and LGMD2A patients did not present significant decrease in functionality in individuals with the mean age of 25.8 and 27.7 years old, respectively. The literature shows evidence that early or later childhood-onset muscle dystrophies, such as DMD, may be associated with profound loss of muscle function, affecting ambulation, posture, and cardiac and respiratory function. Late-onset muscular dystrophies, as SMD and LGMD2A, may be mild and associated with slight weakness or fatigability induced by effort, without significant loss of functionality (Chelly and Desguerre 2013). However, DMD presents a progressive loss of muscle function leading to a decrease of functionality and changes to the quality of life of patients, in the early years of the disease (Wicklund 2013).

It is known that oxidative stress and chronic inflammation are involved in the physiopathology of PMD's (Lawler 2011, Chelly and Desguerre 2013, Wicklund 2013). Disruption of the dystroglycan complex leads to high susceptibility to injury, with repeated, eccentric contractions as well as inflammation, resulting in significant damage and necrosis. Chronic damage and repair cycling leads to fibrosis and weakness. Thus, elevated oxidative stress may contribute to damage, weakness and possibly fibrosis and a decrease of functionality (Lawler 2011). Oxidative stress has been postulated to play an important role in several degenerative conditions (Moosmann and Behl 2002). In the dystrophic muscle, oxidative stress is a potential pathogenetic factor which may determine the severity of the pathology (Kim et al. 2013, Renjini et al. 2012). In this study, it was shown that DMD and SMD patients present a decrease of SOD activity in the serum without alteration in the others oxidative parameters. In the DMD, the most severe PMD, comorbidities such as muscle fatigue and cardiomyopathy are associated with induction oxidative stress in serum (Bia et al. 1999). Moreover, Toscano et al. (2005) demonstrated that SMD patients showed significantly higher activity of SOD in the serum than normal controls. Recently, it was shown oxidative stress in muscle of young LGMD2 patients (Rajakumar et al. 2013). Low levels of antioxidants can be leading to an imbalance oxidative process. However, in our study, the patients have a mean age of 17.9 years for DMD, 25.8 years for SMD and 27.7 years for LGMD2A. At this age, most patients presented low functionality, loss of muscle function and bone deformities. These alterations may contribute to the low SOD activity. Oxidant molecules in the serum may have been consumed by SOD activity at early times when muscle function was possibly better.

Additionally, the cytokines were also evaluated in this study. These substances are mediators of inflammation released by a variety of cell types, and regulate a wide variety of metabolic, inflammatory, and regenerative processes (Ott et al. 1994). The abnormal increase in the level of proinflammatory molecules such as TNF- $\alpha$ and IL- $1 \beta$ has been suggested as being the major mechanism that triggers events leading to muscle wasting (Porreca et al. 1999, Lundberg et al. 1995). In this study, it was found an increase of IL-1 $\beta$ in DMD and SMD patients, an increase of TNF- $\alpha$ only the DMD patients and a decrease of IL-10 in all groups. Patients with DMD were shown to have elevated TNF- $\alpha$ serum levels when compared with controls (Abdel-Salam et al. 2009). Our results show that DMD patients present increase of IL- $1 \beta$ and TNF- $\alpha$ levels and decrease of IL-10, demonstrating an imbalance between pro- and anti-inflammatory activity. Increasing evidence indicates that inflammatory processes are highly integrated into muscle wasting with DMD (Spencer and Tidball 2001). Circulating inflammatory cytokines may be 1000 times higher in DMD human patients than healthy controls (Watanabe 2001). SMD patients 
showed higher levels of IL-1B and lower levels of IL-10; LGMD2D showed lower levels of IL-10. We believe that since these muscular disorders are part of a continuum for PMD there will always be a pro-inflammatory state due to the disease itself and an anti-inflammatory counterpart trying to balance the generated inflammation and perhaps restrain the progressive characteristic of the disease. The major involvement of the inflammatory system observed in patients with DMD when compared with SMD and LGMD2A patients may be involved with the level of functionality or stage of the degenerative.

In addition, PMD patients present cognitive impairment(D'Angelo and Bresolin 2006). During the process of learning and memory formation, the BDNF acts in diverse functions in the adult brain as in learning and memory formation. In our study, it was observed that only SMD patients presented serum BDNF alterations, suggesting a possible brain involvement during the process disease. A recent review study showed that neurodegenerative disorders associated to cognitive impairment such as Huntington's disease, Alzheimer's disease and depression presented low levels of BDNF serum ( $\mathrm{Lu}$ et al. 2014). It is well known that SMD is associated with cognitive impairment, caused by cerebral white matter lesions and brain atrophy (Minnerop et al. 2011, Jakkani et al. 2012). The CNS symptoms of SMD may include cognitive impairment, hypersomnolence, heightened sensitivity to anesthetic agents, central hypoventilation, neuroendocrine dysfunction, and personality and behavior disturbances (D'Angelo and Bresolin 2006). However, studies involving humans with DMD, SMD or LGMD2 evaluating BDNF have not been conducted. These results are, to our knowledge, the first evidence of BDNF involvement in the SMD process in patients.

Some limitations should be mentioned: (1) we evaluated the oxidative damage and inflammatory molecules in serum, thus we might not clearly explain what is causing these changes and (2) more analyses are needed to elucidate the brain involvement in PMD. In conclusion, this study showed that DMD patients present decrease of functionality levels associated with decrease of SOD activity and IL-10 levels and an increase of IL-1 $\beta$ and TNF- $\alpha$ levels; SMD patients present a decrease in BDNF and IL-10 levels and SOD activity and an increase of IL-1 $\beta$ levels; and LGMD2A present only an increase of IL-10 levels. We believe that these results might be associated with the stage of the disease and functionality since DMD patients have a severe inflammatory system involvement and decrease of functionality, unlike LGMD2A patients who only have decrease of IL-10 levels and functionality preserved. Moreover, this research showed the first evidence of BDNF involvement in SMD patients and a possible unbalance between pro- and anti-inflammatory parameters in DMD and SMD, along with decreased SOD activity.

\section{RESUMO}

Nós investigamos os níveis do Fator Neurotrófico Derivado do Cérebro (BDNF), citosinas e parâmetros oxidativos em soro e correlacionamos com a idade e funcionalidade dos pacientes com Distrofias Musculares Progressivas (PMD). Os pacientes foram separados em seis grupos (casos e controles pareados por idade e sexo), como segue: Distrofia Muscular de Duchenne (DMD); Distrofia Miotônica de Steinert (SMD); e Distrofia Muscular de Cinturas do tipo 2A (LGMD2A). Pacientes com DMD $( \pm 17,9$ anos de idade) tiveram uma diminuição da funcionalidade, aumento nos níveis de IL-1 $\beta$ e TNF- $\alpha$ e uma diminuição dos níveis de IL10 e da atividade da superóxido dismutase no soro. Pacientes com SMD ( $\pm 25,8$ anos de idade) tiveram uma diminuição dos níveis de BDNF e IL-10 e da atividade da superóxido dismutase e um aumento dos níveis de IL-1 $\beta$ no soro. Pacientes com LGMD2A ( $\pm 27,7$ anos de idade) tiveram uma diminuição somente nos níveis de IL-10 no soro. Esta pesquisa mostrou a primeira evidência do envolvimento dos níveis de BDNF em pacientes com SMD e um possível desequilíbrio entre fatores pró e 
antiinflamatórios de citosinas e uma diminuição da atividade da superóxido dismutase em soro de pacientes com DMD e SMD.

Palavras-chave: Distrofias Musculares Progressivas, BDNF, citosinas, estresse oxidativo.

\section{ACKNOWLEDGMENTS}

This research was supported by grants from $\mathrm{CNPq}$ (CMC, FK, FD-P, JQ and MIR), UNESC (FD-P, JQ and MIR) and UNISUL (CMC). FK, FD-P and JQ are Conselho Nacional de Desenvolvimento Científico e Tecnológico (CNPq) Research Fellows.

\section{REFERENCES}

AbDel-Salam E, AbDel-Meguid I AND KorRaA SS. 2009. Markers of degeneration and regeneration in Duchenne muscular dystrophy. Acta Myol 28: 94-100.

AEBI H. 1984. Catalase in vitro. Methods Enzymol 105: 121-126.

BANNISTER JV AND CALABRESE L. 1987. Assays for superoxide dismutase. Methods Biochem Anal 32: 279-312.

Bia B, CAssidy P, Young M, Rafael JA, Leighton B, DAVIES KE, RADDA GK AND Clarke K. 1999. Decreased myocardial nNOS, increased iNOS and abnormal ECGs in mouse models of Duchenne muscular dystrophy. J Mol Cell Cardiol 31: 1857-1862.

BRAMHAM CR AND MESSAOUdI E. 2005. BDNF function in adult synaptic plasticity: the synaptic consolidation hypothesis. Prog Neurobiol 76: 99-125.

Chelly J And Desguerre I. 2013. Progressive muscular dystrophies. Handb Clin Neurol 113: 1343-1366.

D'ANGElo MG AND BRESOLIN N. 2006. Cognitive impairment in neuromuscular disorders. Muscle Nerve 34: 16-33.

EMERY AE. 1998. The muscular dystrophies. BMJ 317: 991-995.

ESTERBAUER H AND CHEESEMAN KH. 1990. Determination of aldehydic lipid peroxidation products: malonaldehyde and 4-hydroxynonenal. Methods Enzymol 186: 407-421.

FANZANi A, MONTI E, DONATO R AND SORCI G. 2013. Muscular dystrophies share pathogenetic mechanisms with muscle sarcomas. Trends Mol Med 19: 546-554.

Guglieri M, MAGRI F AND COMI GP. 2005. Molecular etiopathogenesis of limb girdle muscular and congenital muscular dystrophies: boundaries and contiguities. Clin Chim Acta 361: 54-79.

HARPER PS. 1989. Myotonic dystrophy, $2^{\text {nd }}$ ed., Philadelphia: Saunders,

ITO Y, OUMI S, NAGASAWA T AND NISHIZAWA N. 2006. Oxidative stress induces phosphoenolpyruvate carboxykinase expression in H4IIE cells. Biosci Biotechnol Biochem 70: 2191-2198.

JAKKANi R, JYOTI S, AHMED M AND THOMAS MM. 2012. Magnetic resonance imaging findings in adult-form myotonic dystrophy type 1 . Singapore Med J 6: 150-152.
JAMALUDDIN M, WANG S, BOLDOGH I, TIAN B AND BRASIER AR. 2007. TNF-alpha induced NFkappaB/ RelA Ser(276) phosphorylation and enhanceosome formation is mediated by an ROS-dependent PKAc pathway. Cell Signal 19: 1419-1433.

KIM JH, KWAK HB, THOMPSON LV AND LAWLER JM. 2013. Contribution of oxidative stress to pathology in diaphragm and limb muscles with Duchenne muscular dystrophy. J Muscle Res Cell Motil 34: 1-13.

KoenIG M ET AL. 1989. The molecular basis for Duchenne versus Becker muscular dystrophy: correlation of severity with type of deletion. Am J Hum Genet 45: 498-506.

LAWLER JM. 2011. Exacerbation of pathology by oxidative stress in respiratory and locomotor muscles with Duchenne muscular dystrophy. J Physiol 589: 2161-2170.

LeVine RL, Williams JA, StadtMan ER AND SHActer E. 1994. Carbonyl assays for determinationof oxidatively modified proteins. Methods Enzymol 233: 346-357.

LOwry OH, ROSEBrough NJ, FARR AL AND RANDALL RJ. 1951. Protein measurement with the Folin phenol reagent. J Biol Chem 193: 265-275.

LU B, NAGAPPAN G AND LU Y. 2014. BDNF and synaptic plasticity, cognitive function, and dysfunction. Handb Exp Pharmacol 220: 223-250.

LundBERG I, BRENGMAN JM AND ENGEL AG. 1995. Analysis of cytokine expression in muscle in inflammatory myopathies, Duchenne dystrophy, and non-weak controls. J Neuroimmunol 63: 9-16.

MINNEROP M ET AL. 2011. The brain in myotonic dystrophy 1 and 2: evidence for a predominant white matter disease. Brain 6: 3530-3546.

Moosmann B AND BeHL C. 2002. Antioxidants as treatment for neurodegenerative disorders. Expert Opin Investig Drugs 11: 1407-1435.

Ott L, McClain CJ, Gillespie M and Young B. 1994. Cytokines and metabolic dysfunction after severe head injury. J Neurotrauma 11: 447-472.

Porreca E, Guglielmi MD, Uncini A, Di Gregorio P, ANGelini A, Di FebBo C, Pierdomenico SD, BACCANTE G AND CUCCURULlo F. 1999. Haemostatic abnormalities, cardiac involvement and serum tumor necrosis factor levels in X-linked dystrophic patients. Thromb Haemost 81: 543-546.

RAJAKUMAR D, AlEXANDER M AND OOMMEN A. 2013. Oxidative stress, NF- $\mathrm{kB}$ and the ubiquitin proteasomal pathway in the pathology of calpainopathy. Neurochem Res 38: 2009-2018.

RENJINI R, GAYATHRI N, NALINI A AND SRINIVAS BHARATH MM. 2012. Oxidative damage in muscular dystrophy correlates with the severity of the pathology: role of glutathione metabolism. Neurochem Res 37: 885-898.

SinOfF G AND ORE L. 1997. The Barthel Activities of Daily Living Index: selfreporting versus actual performance in the old-old (> 75 years). J Am Geriatr Soc 45: 832-835.

SPENCER MJ AND TIDBALL JG. 2001. Do immune cells promote the pathology of dystrophin-deficient myopathies? Neuromuscul Disord 11: 556-564. 
TIDBALL JG AND WEHLING-HENRICKS M. 2007. The role of free radicals in the pathophysiology of muscular dystrophy. J Appl Physiol 102: 1677-1686.

Toscano A, Messina S, Campo GM, Di Leo R, Musumeci O, Rodolico C, Aguennouz M, ANNEsi G, Messina C AND VITA G. 2005. Oxidative stress in myotonic dystrophy type 1. Free Radic Res 39: 771-776.
WATANABE N. 2001. Clinical significance of measurement of circulating tumor necrosis factor. Jap J Clin Pathol 49: 829-833.

WiCKLUND MP. 2013. The muscular dystrophies. Continuum (Minneap Minn) 19: 1535-1570. 